\title{
Citomegalovírus: epidemiologia baseada em dados de soroprevalência
}

\section{Cytomegalovirus: epidemiology based on seroprevalence data}

\author{
Dorotéa de Fátima Lobato-Silva
}

Instituto Evandro Chagas/SVS/MS, Seção de Meio Ambiente, Ananindeua, Pará, Brasil

\begin{abstract}
RESUMO
O citomegalovírus humano (HCMV) é um dos principais agentes causadores de diversos agravos mórbidos nos períodos pré e pós-natal. De acordo com os dados soroepidemiológicos, esse agente é altamente prevalente no mundo com diferentes taxas de infecção nos diversos estratos da sociedade e regiões geográficas. A elevada prevalência está principalmente associada a fatores socioeconômicos, aos maus hábitos de higiene, às péssimas condições de saneamento básico e ao nível cultural das populações, sobretudo aquelas procedentes de países em desenvolvimento. Neste artigo são avaliados os fatores que contribuem para manter o perfil soroepidemiológico do HCMV, buscando conhecer os atuais índices de soroprevalência da infecção em grupos de indivíduos de diferentes localizações geográficas, nas diversas faixas etárias.
\end{abstract}

Palavras-chaves: Citomegalovírus; Soroepidemiologia; Transmissão Viral; Fatores de Risco.

\begin{abstract}
Human cytomegalovirus (HCMV) is one of the main causes of several morbid diseases during pre- and postnatal periods. Seroepidemiologic data indicate that HCMV has a high prevalence worldwide with infection rates varying with social strata and geographic regions. Its high prevalence is mainly associated with socioeconomic factors, poor hygiene, poor sanitary conditions, and cultural standards, especially in developing countries. This article aimed to evaluate factors that contribute to the seroepidemiologic profile of HCMV, as well as investigate its current seroprevalence with respect to geographic location and age.
\end{abstract}

Keywords: Cyłomegalovirus; Seroepidemiology; Virus Transmission; Risk Factors.

\section{INTRODUÇÃO}

O citomegalovírus humano (HCMV) é um agente ubíquo, que acomete pessoas de todas as classes sociais de diferentes raças e faixas etárias, sendo altamente prevalente principalmente em populações dos continentes sul-americano e africano. De acordo com Pannuti', as mais altas prevalências estão relacionadas a fatores socioeconômicos e culturais das populações, acometendo mais indivíduos de baixa renda, dadas as condições de educação, higiene e saneamento básico.

A infecção pode ocorrer tanto por vias naturais como iatrogênicas e a aquisição do vírus inicia desde a infância, aumentando proporcionalmente com a idade $^{1,2}$. O vírus é considerado uma das principais causas de infecção congênita e perinatal, enquanto que no período pós-natal é grave para indivíduos com imunodeficiência ${ }^{3,4,5,6,7,8,9,10}$.

Após a primeira infecção, o HCMV pode permanecer no organismo indefinidamente e ser ativado, ocasionando novos episódios de infecção, sendo essa forma muito comum em indivíduos

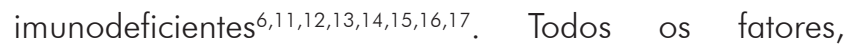
acima relacionados, convergem para elevar sua prevalência nos diversos grupos populacionais de diferentes estratos da sociedade e regiões geográficas; assim, é importante conhecer a epidemiologia viral do HCMV e os fatores que contribuem para aumentar sua endemicidade de tal forma que medidas de controles sejam aplicadas para monitorar a cadeia de transmissão do vírus. 


\section{TRANSMISSÃO}

O HCMV é um importante agente infeccioso causador de diversas patologias que podem cursar tanto de forma sintomática quanto assintomática, disseminada ou em órgão específico ${ }^{17}$.

A infecção viral pode ocorrer em diferentes períodos de vida do indivíduo, estando relacionada a fatores socioeconômicos e culturais, além da presença do agente em diversos fluidos orgânicos, os quais conjuntamente contribuem para elevar a endemicidade e disseminação do vírus ${ }^{1,4,18,19}$.

A transmissão viral pode ocorrer por vias naturais ou iatrogênicas ${ }^{1,2}$, sendo que as vias naturais mais comuns estão relacionadas ao contato íntimo e repetitivo da pessoa sadia com secreções do doente. Nesse caso, familiares, profissionais de saúde e cuidadores infantis ou pré-escolares ficam mais propensos a adquirir o vírus.

As crianças são consideradas importantes na cadeia de transmissão viral, pois excretam o vírus pela urina e saliva por tempo indeterminado 7,20 . Enquanto que, na fase adulta, os jovens são os principais transmissores da doença, pois a via sexual passa a ser a principal forma de transmissão horizonta|21,22.

A precocidade na aquisição do vírus também está relacionada à transmissão durante a gestação, chamada de vertical ou pré-natal. Essa forma de infecção desenvolve-se por meio da placenta ${ }^{7,23,24}$, ocasionando a infecção do feto. Se a transmissão materno-fetal ocorrer por infecção primária materna, a infecção congênita tem grandes possibilidades de causar graves prejuízos para 0 feto em desenvolvimento, principalmente, se acontecer no primeiro trimestre de gravidez ${ }^{25}$.

Nos casos mais graves da infecção fetal, a criança pode apresentar surdez neurosensorial, hidrocefalia, calcificações intracranianas, prematuridade, microcefalia, tamanho pequeno para a idade gestacional e outros. Se a infecção no feto ocorrer por reativação da cepa endógena materna, então os prejuízos para a criança serão minimizados pela ação dos anticorpos maternos anti-HCMV da primoinfecção ${ }^{7,24}$.

Por outro lado, quando a criança não é afetada na fase do desenvolvimento uterino, ela poderá adquirir o vírus durante a passagem pelo canal do parto ou nas primeiras mamadas, sendo denominada de transmissão perinatal por vias iatrogênicas ${ }^{1,7,8}$.

Outra forma de transmissão iatrogênica é dada pelo compartilhamento de seringas e agulhas no uso de drogas injetáveis, utilização de instrumentos na colocação de piercings e tatuagens, além de transfusão sanguínea, transplantes de órgãos e processos de diálises ${ }^{1,26,27,28,29}$.

$\bigcirc$ vírus pode permanecer no organismo indefinidamente após a primeira infecção e, em determinadas situações de baixa imunidade do hospedeiro, o HCMV pode ser ativado do seu estado de latência e causar infecções recorrentes ${ }^{15,16,30}$.
A infecção recorrente é um tipo de infecção secundária ocasionada por reativação da cepa endógena ou cepa exógena, quando há transmissão por via iatrogênica. Esse mecanismo de infecção é comum em indivíduos submetidos a determinados procedimentos terapêuticos e cirúrgicos, ocasionando manifestações clínicas importantes por comprometer diversos sistemas do organismo ${ }^{18,31,32,33,34}$.

\section{DISTRIBUIÇÃO MUNDIAL}

Os dados soroepidemiológicos de diferentes regiões do mundo demonstram que a infecção pelo HCMV é frequente em comunidades de baixo nível socioeconômico. Esses dados também indicam que existe uma relação proporcionalmente inversa entre a suscetibilidade e o status socioeconômico, ou seja, grupos populacionais com nível socioeconômico elevado apresentam maior suscetibilidade e, consequentemente, menor imunidade ao vírus, ao passo que indivíduos de baixo poder aquisitivo apresentam maior imunidade e menor suscetibilidade à doença ${ }^{5,35,36}$.

As maiores taxas de soroprevalência para o HCMV ocorrem em populações procedentes de países em desenvolvimento, cujos índices variam entre 80-100\%, e em populações de países desenvolvidos entre $40-60 \%^{1,29,37,38}$. A elevada frequência de anticorpos na população economicamente menos favorecida está relacionada aos maus hábitos de higiene, às péssimas condições de saneamento básico, à moradia e à educação das populações ${ }^{2}$. Certamente que o conjunto desses fatores, associados à biologia viral e à deficiência imunológica, contribuem para a manutenção do perfil epidemiológico do vírus na população.

Os índices de infecção congênita em diferentes populações do mundo foram estimados entre $0,2 \%$ e $3,2 \% 3,4,19,20,39,40,41$, sendo que Lanzieri et $a^{42}$ demonstraram, em uma revisão epidemiológica sistemática de dados obtidos de vários estudos realizados, entre o período de 1978 a 2011, que as taxas de infecção congênita por HCMV em populações de países em desenvolvimento variam entre 0,6\% e 6,1\%.

Um amplo estudo conduzido em Portugal sobre a frequência de anticorpos anti-HCMV, realizado em 2.143 amostras, demonstrou que $77 \%$ dos indivíduos estudados já haviam sido infectados pelo HCMV e, aproximadamente, $66 \%$ da amostra era da faixa etária de 2 a 4 anos, confirmando a aquisição da infecção pelo HCMV nos primeiros anos de vida ${ }^{43}$. Outros estudos comprovaram que a prevalência de anticorpos anti-HCMV inicia na infância e aumenta proporcionalmente com a idade, tendo maior predomínio de anticorpos após os 25 anos, estando esse aumento relacionado ao início da atividade sexual do indivíduo ${ }^{44}$.

Apesar da variação nas taxas de soroprevalência em populações dos diferentes continentes, elas não estão relacionadas à distribuição geográfica, mas ao nível socioeconômico' ', como demonstrado na figura 1 . 

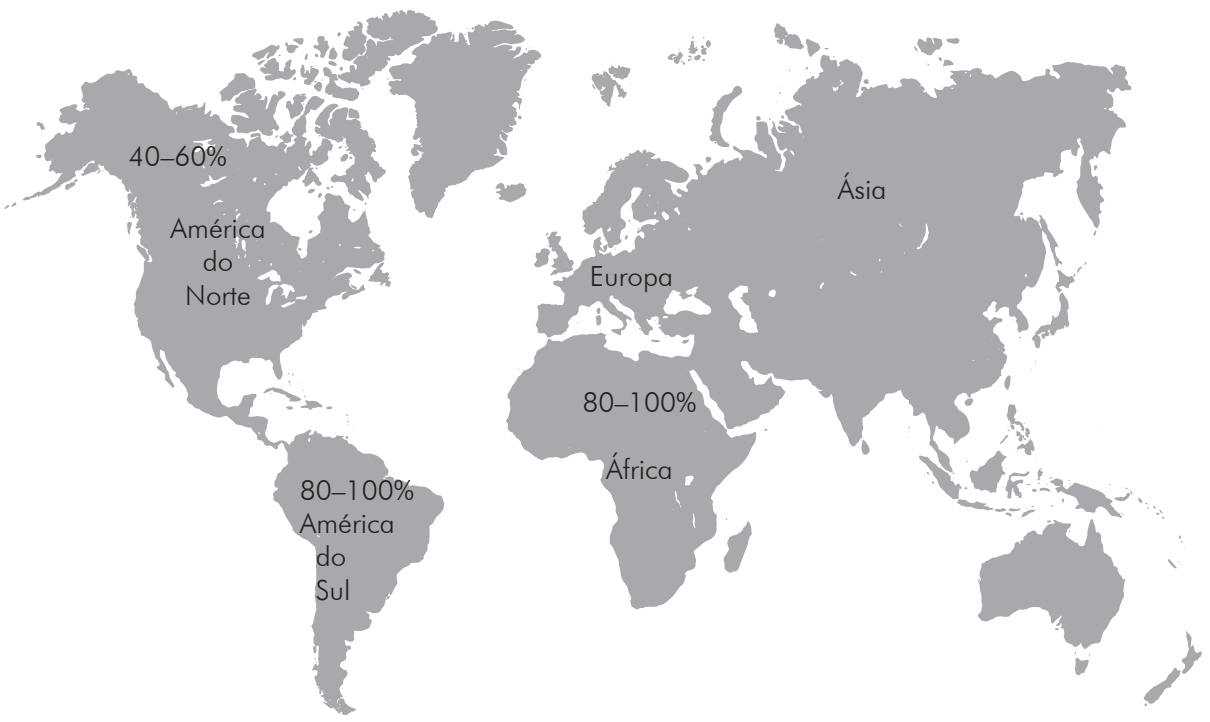

Fonte: Baseado em dados de Panutti ${ }^{37}, 1996$.

Figura 1 - Distribuição da frequência de anticorpos lgG anti-HCMV nos diferentes continentes

Nos Estados Unidos, aproximadamente 60\% dos indivíduos acima de 6 anos de idade são infectados pelo HCMV. De acordo com Staras et $\mathrm{al}^{45}$, essa estimativa é compatível com os índices de soroprevalência em populações da Inglaterra e Alemanha, sendo superior ao observado no Canadá, e inferior ao registrado na Índia, Israel, Chile, Peru e Arábia Saudita.

Um estudo soroepidemiológico realizado na Palestina demonstrou elevada frequência de anticorpos IgG anti-HCMV em mais de $88 \%$ entre crianças, grávidas e recém-nascidos hospitalizados. A infecção por HCMV demonstrada na pesquisa de anticorpos IgM foi positiva em 11,5\% das gestantes, 11,7\% nas crianças e em $2 \%$ em recém-nascidos hospitalizados ${ }^{46}$.

Foram registrados elevados índices de soroprevalência de anticorpos para o HCMV em mulheres de diversos países africanos, como $87 \%$ em Gambia, 97,2\% em Benin e $96 \%$ no Egito. No Sudão, foram registrados $72,2 \%$ de anticorpos em gestantes, sendo que nos países do sudeste africano são encontradas as maiores frequências de anticorpos para o $\mathrm{HCMV}^{47}$. Os percentuais sobre a soroprevalência de anticorpos relacionados ao continente euro-asiático ainda não foram estabelecidos como os de outros continentes, por essa razão não estão representados na figura 1 .

\section{ESTIMATIVA DE PREVALÊNCIA NO BRASIL}

A maioria dos dados sobre a prevalência do HCMV tem origem em estudos conduzidos por grupos de pesquisadores da Região Sudeste. Embora no Brasil poucos registros tenham sido feitos a cerca da situação soroepidemiológica do HCMV, alguns trabalhos têm documentado que a idade média de aquisição do vírus no período pós-natal pode estar compreendida entre 5 meses e 18 anos de idade e que as mulheres em idade fértil são as mais vulneráveis à primoinfecção ${ }^{48}$.

Numa ampla análise realizada em 1.045 amostras de doadores de sangue do Estado de Santa Catarina, constatou-se que a prevalência de anticorpos lgG para o HCMV era de $96,45 \%$ e de 2,3\% para anticorpos lgM, sugestivo de infecção recente ${ }^{49}$. A taxa de soroprevalência foi tão elevada quanto em outros grupos de regiões geográficas de países em desenvolvimento.

Serra et $a^{50}$ compilaram dados de soroprevalência de anticorpos anti-HCMV de 4.620 amostras de gestantes e puérperas do Rio de Janeiro, São Paulo e de outros Estados brasileiros, sendo investigados anticorpos lgG e IgM anti-HCMV. Os índices de soroprevalência foram variáveis entre 50\% e 100\% nos diferentes Estados, e de acordo com os autores, os índices não deveriam refletir a realidade epidemiológica do vírus na análise, devido à diferença no tamanho amostral de cada Estado.

Por outro lado, quando esses dados são estratificados por tamanho amostral, percebe-se que, tanto em pequeno número de amostras quanto no elevado tamanho amostral, as frequências são elevadas em todos os casos.

O total de amostras procedentes de mulheres do Rio de Janeiro e de São Paulo estava compreendido entre 1.400 e 1.500 amostras, sendo esses valores bastante representativos para uma análise em um grupo específico. As frequências de anticorpos foram de $78,7 \%$ para as amostras do Rio de Janeiro e de $84,8 \%$, para amostras de São Paulo. Nos Estados da Bahia, Distrito Federal, Minas Gerais, Santa Catarina e Rio Grande do Sul, o tamanho amostral variou de 95 a 150 amostras, sendo a menor frequência observada no Estado da Bahia, com 78\%; e a maior, com 88\% no Rio Grande do Sul. Os cinco Estados que apresentaram frequência igual a 100\% foram: Espírito Santo, Mato Grosso, Pernambuco, Rondônia e Roraima, sendo que o tamanho amostral não foi representativo abaixo de 10 amostras (Figura 2). No Estado do Acre, a frequência foi igual a zero, em função de ter sido obtida apenas uma amostra e com sorologia negativa. 


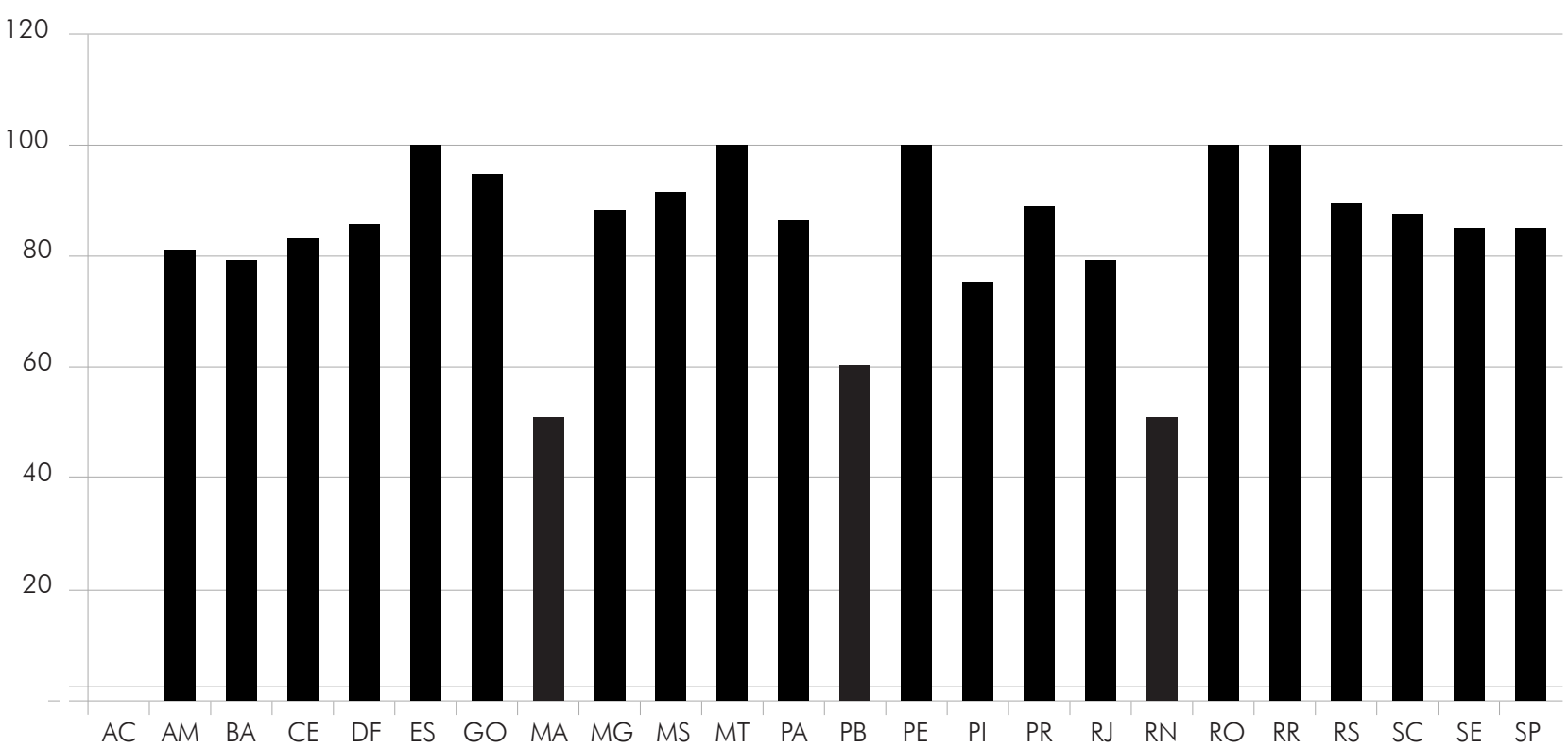

Figura 2 - Soroprevalência do HCMV, segundo Serra et al50, 2009

Na Região Norte do Brasil, Cidade de Belém, Estado do Pará, alguns trabalhados têm sido publicados estimando a soroprevalência e os índices de infecção do HCMV em diferentes grupos de indivíduos e faixas etárias.

Na década de 1990, Weirich ${ }^{20}$ utilizou dois métodos laboratoriais diferentes para avaliar índices de infecção congênita por $\mathrm{HCMV}$, sendo observada variação nas taxas de infecção correspondentes a 2,1\% pelo método sorológico e a 3,2\% por isolamento viral. Também foi observado que $90,2 \%$ das puérperas possuíam anticorpos de infecção pregressa e menos de $1 \%$ apresentava infecção ativa por HCMV.

Estudos realizados por Silva et $\mathrm{al}^{15}$, em 2007, sobre a infecção por HCMV em pacientes pré e pós-transplante renal por métodos sorológico e molecular, constataram aumento na soroprevalência e nos índices de infecção após transplante do enxerto. No período pré-transplante, a frequência de anticorpos era de $78,5 \%$ e de $100 \%$ após o transplante, enquanto os índices de infecção ativa, antes do enxerto, eram de $7,1 \%$, passando para $14,5 \%$ depois do transplante. Esses dados demonstram 0 fato de que a relação R-/D+ foi o fator crítico para o desenvolvimento da doença nesse grupo de pacientes. No mesmo ano, Medeiros et $a^{28}$ realizaram a pesquisa viral para - HCMV em amostras sanguíneas, por métodos moleculares, em um grupo de 115 doadores de sangue da Fundação Centro de Hemoterapia e Hematologia do Pará, observando que $57 \%$ eram portadores do HCMV. Esses dados corroboram os achados de Silva et $\mathrm{al}^{15}$ quanto à relação R/D e reforçam a dificuldade de se ter doadores soronegativos para o HCMV.

Em 2011, Silva et al ${ }^{9}$ realizaram análises em pacientes de Belém com diferentes quadros de imunodeficiência e demonstraram que a prevalência de anticorpos para o HCMV era de $87 \%$ e o de infecção, de 13\%. Outro estudo realizado por Silva et $a^{\left.\right|^{51}}$ sobre a distribuição de anticorpos anti-HCMV, em mulheres gestantes e em idade fértil da faixa etária de 14 a 29 anos, do Município de Juruti, Estado do Pará, demonstrou elevados índices de soroprevalência correspondentes a $87,8 \%$ e a $82,3 \%$, respectivamente. Nesse estudo, não houve deteç̧ão de anticorpos de infecção aguda.

Dados mais recentes, publicados por Silva et a ${ }^{52}$, demonstraram que a soroprevalência em um grupo de 241 pacientes, vivendo com HIV/aids, era de aproximadamente $100 \%$ e somente $2,1 \%$ apresentavam infecção aguda pelo método sorológico; porém, na análise por métodos moleculares, mais de $50 \%$ dos pacientes apresentaram infecção ativa com carga viral $>1.000$ cópias $/ \mathrm{mL}$. Esses dados demonstram que os índices de infecção por HCMV são subestimados em decorrência do método utilizado, principalmente na ausência de manifestações clínicas.

Diante do cenário soroepidemiológico demonstrado nesta revisão, há a necessidade de estudos que visem à introdução de medidas profiláticas, como a vacina, para que haja mudança no perfil soroepidemiológico do vírus, principalmente nas populações economicamente menos favorecidas, onde as taxas de soroprevalência são elevadas.

\section{CONCLUSÃO}

Por meio do perfil soroepidemiológico do vírus, constata-se que não foi estabelecida uma taxa de soroprevalência do HCMV no Brasil; isso se deve, provavelmente, ao fato de que existem poucos dados publicados sobre o assunto. Embora os dados de Serra et a ${ }^{50}$ não devam ser considerados como representativos, em função do tamanho amostral, foi notório que, tanto no tamanho amostral baixo quanto alto, a soroprevalência, em sua maioria, era acima de $75 \%$, o que é consideravelmente próximo dos valores de soroprevalência em países em desenvolvimento, ou seja, o HCMV é bastante prevalente e esse fato favorece sua transmissão. 
É indiscutível que fatores, como a relação sexual desprotegida, multiplicidade de parceiros, a relação receptor-doador de órgãos, transfusões sanguíneas, entre outros, são críticos e contribuem para a transmissão da doença. Todos eles somados à endemicidade e aos fatores socioeconômicos das populações, principalmente aquelas de países em desenvolvimento, mantêm o perfil soroepidemiológico do vírus como um dos mais prevalentes no mundo.

É fundamental a realização de estudos de prevalência mais abrangentes que possam determinar os índices regionais de infecção por HCMV no Brasil, considerando-se, principalmente, fatores socioeconômicos e culturais próprios de cada região, assim como as características biológica epidemiológica desse agente e sua importância na saúde humana.

É importante a introdução de métodos moleculares como instrumento de análise para avaliar a magnitude da infecção e o caráter endêmico do vírus, pois, com esses métodos, é possível detectar índices de infecção ativa mesmo na ausência de sinais e sintomas clínicos e na presença de anticorpos de alta avidez.

Diante desse panorama, é necessária a introdução de medidas educativas e de saneamento básico, enquanto não são introduzidas medidas profiláticas eficazes, como a vacina, para que haja mudança no perfil epidemiológico da infecção, principalmente nas populações de baixa renda.

\section{REFERÊNCIAS}

1 Pannuti C. Citomegalovirose. In: Focaccia R, Veronesi R, editores. Tratado de infectologia. São Paulo: Atheneu; 2009. p. 363-71.

2 Mendrone Junior A. Prevalência da infecção pelo citomegalovírus: a importância de estudos locais. Rev Bras Hematol Hemoter. 2010 fev;32(1):7-8.

3 Stagno S, Reynolds DW, Huang E-S, Thames SD, Smith RJ, Alford CA. Congenital cytomegalovirus infection - occurrence in an immune population. N Engl J Med. 1977 Jun;296(22):1254-8.

4 Stagno S, Reynolds DW, Pass RF, Alford CA. Breast milk and the risk of cytomegalovirus infection. $N$ Engl J Med. 1980 May;302(19):1073-6.

5 Stagno S, Pass RF, Dworsky ME, Henderson RE, Moore EG, Walton PD, et al. Congenital cytomegalovirus infection - the relative importance of primary and recurrent maternal infection. $\mathrm{N}$ Engl J Med. 1982 Apr;306(16):945-9.

6 Pass RF. Cytomegalovirus infection. Pediatr Rev. 2002 May;23(5): 163-70.

7 Yamamoto AY, Mussi-Pinhata MM, Figueiredo LTM. Infecção congênita e perinatal por citomegalovírus aspectos clínicos, epidemiologia, diagnóstico e tratamento. Medicina. 1999 jan-mar;32: 49-56.

8 Yamamoto AY, Figueiredo LTM, Mussi-Pinhata MM. Infecção perinatal por citomegalovírus: muito freqüente mas pouco diagnosticada. J Pediatr. $1999 ; 75(2): 126-30$.

9 Silva DL, Medeiros RLF, Moraes MM, Espírito Santo FS. Restriction enzyme analysis of the human cytomegalovirus genome in specimens collected from immunodeficient patients in Belém, State of Pará, Brazil. Rev Soc Bras Med Trop. 2011 SepOct;44(5):551-4.
10 Yamamoto AY, Mussi-Pinhata MM, Isaac ML, Amaral FR, Carvalheiro CG, Aragon DC, et al. Congenital cytomegalovirus infection as a cause of sensorineural hearing loss in a highly immune population. Pediatr Infect Dis J. 2011 Dec;30(12):1043-6.

11 Pannuti CS, Vilas Boas LS, Amato Neto V, Angelo MJO, Sabbaga E. Detecção de anticorpos IgM nas infecções primárias e secundárias pelo citomegalovírus em pacientes submetidos a transplante renal. Rev Inst Med Trop S Paulo. 1987 set-out;29(5):317-22.

12 Diniz EMA, Costa FAV. Infecção pelo citomegalovírus. Rev IMIP. 1988 jun;2(2):150-4.

13 Taylor-Wiedeman J, Sissons JGP, Borysiewicz LK, Sinclair JH. Monocytes are a major site of persistence of human cytomegalovirus in peripheral blood mononuclear cells. J Gen Virol. 1991 Sep;72(Pt 9):2059-64.

14 Mocarski ES. Cytomegaloviruses and their replication. In: Fields BN, Knipe DM Howley PM, editors. Fields virology. 3rd ed. New York: Lippincott-Raven; 1996. p. 2447-92.

15 Silva DFL, Gomes RHS, Moraes MM, Medeiros RFL, Santos ECO, Jesus IM. Perfil sorológico e molecular da infecção pelo citomegalovírus em pacientes transplantados de Belém-PA. Cad Saude Coletiva. 2007 jul-set; 15(3):369-78.

16 Lorenzi JCC, Coelho-Castelo AAM. Resposta imune contra infecções virais. Scire Salutis. 2011 set; $1(2): 35-44$.

17 Arce-Salinas CA, Villasenor-Ovies P. Infections and systemic lupus erythematosus. In: Almoalilin $H$, editor. Systemic lupus erythematosus. Rijeka (CRO): InTech; 2012. 554 p.

18 Britt WJ, Alford CA. Cytomegalovirus. In: Fields BN, Knipe DM, Howley PM, editors. Fields virology. 3rd ed. Vol. 2. New York: Lippincott-Raven; 1996. p. 2493-523. 
19 Oliveira FL, Braga A, Caputo A, Rezende-Filho JF, Montenegro CAB. Infecção pelo citomegalovírus na gestação: uma visão atual. Femina. 2011 nov;39(1 1):515-9.

20 Weirich J. Infecção congênita pelo citomegalovírus: estudo realizado na Fundação Santa Casa de Misericórdia do Pará. Rev Soc Bras Med Trop. 1998 mai-jun;31(3):325-6.

21 van der Meer JT, Drew WL, Bowden RA, Galasso GJ, Griffiths PD, Jabs DA, et al. Summary of the international consensus symposium on advances in the diagnosis, treatment and prophylaxis of cytomegalovirus infection. Antiviral Res. 1996 Nov;32(3): $119-40$.

22 Carraro E. Caracterização genotípica do citomegalovírus humano em transplantados renais [dissertação]. São Paulo (SP): Universidade Federal de São Paulo; 2001. 107 p.

23 Naddeo F, Passos-Castilho AM, Granato C. Cytomegalovirus infection in pregnancy. J Bras Patol Med Lab. 2015 Sep-Oct;51(5):310-4.

24 Leung AKC, Sauve RS, Davies DH. Congenital cytomegalovirus infection. J Natl Med Assoc. 2003 Mar;95(3):213-8.

25 Palhares DB, Xavier PCN. Citomegalovirose neonatal [Internet]. Rio de Janeiro: SBP; 2011 [citado 2016 abr 25]. Disponível em: www.sbp. com.br/src/uploads/2015/02/Citomegalovirose neonatal.pdf.

26 Nichols GW, Price T, Boeckh M. Cytomegalovirus infections in cancer patients receiving granulocyte transfusions. Blood. 2002 May;99(9):3483-4.

27 Ljungman P. Risk of cytomegalovirus transmission by blood products to immunocompromised patients and means for reduction. Br J Haematol. 2004 Apr;125(2): 107-16.

28 Medeiros RLF, Lemos JAR, Assis MFL, Jesus $I M$, Santos ECO. Detecção do citomegalovírus humano em doadores de sangue através de PCR em tempo real. Cad Saude Coletiva. 2007 julset; 15(3):393-400.

29 Junqueira JJM, Sancho TM, Santos VA. Citomegalovírus: revisão dos aspectos epidemiológicos, clínicos, diagnósticos e de tratamento. Newslab. 2008;86:88-104.

30 Silva DFL, Matos MM, Jesus MI, Santos ECO. Diagnóstico molecular de infecção por citomegalovírus: relato de caso. Rev Para Med. 2005 abr-jun; 19(2):71-6.

31 Drew WL. Cytomegalovirus infection in patients with AIDS. Clin Infect Dis. 1992 Feb;14(2): 608-15.
32 Lima DB, Fernandes O, Gomes VR, Silva EJ, Pinho PRA, Paiva DD. Perfil clínico da enterocolite por citomegalovírus (CMV) na síndrome da imunodeficiência adquirida (Aids). Rev Assoc Med Bras. 2000 jan-mar;46(1):1-6.

33 Caran EM, Petrilli AS, Bordin JO, Castelo Filho A, Tomiyama HT, Pucca LE. Prevalence of cytomegalovirus in a pediatric oncology unit. Acta Oncol Bras. 2000 Jul-Sep;20(3):114-7.

34 Mariguela VC, Chacha SGF, Cunha AA, Troncon LEA, Zucoloto S, Figueiredo LTM. Cytomegalovirus in colorectal cancer and idiopathic ulcerative colitis. Rev Inst Med Trop S Paulo. 2008 MarApr;50(2):83-7.

35 Pannuti CS, Vilas-Boas LS, Angelo MJO, Carvalho RPS, Segre CM. Congenital cytomegalovirus infection. Ocurrence in two socioeconomically distinct populations of a developing country. Rev Inst Med Trop S Paulo. 1985 Mar-Apr;27(2): 105-7.

36 Linhares MIS, Andrade GP, Coelho AF, Tateno $S$, Eizuru $Y$, Minamishima $Y$. Prevalence of cytomegalovirus antibodies in Brazilian women of childbearing age and newborns. Acta Paediatr Jpn. 1989 Oct;31(5):620-2

37 Pannuti CS. Citomegalia. In: Veronesi R, Focaccia R. Tratado de infectologia. São Paulo: Atheneu; 1996. p. 187-94.

38 Santos NJS, Tayra A, Silva SR, Buchalla CM, Laurenti R. AIDS in the State of São Paulo. Changes in the profile of the epidemic and prospects for epidemiological surveillance. Rev Bras Epidemiol. 2002 Dec;5(3):286-310

39 Birnbaum G, Lynch JI, Margileth AM, Lonergan WM, Sever JL. Cytomegalovirus infections in newborn infants. J Pediatr. 1969 Nov;75(5): 789-95.

40 Starr JG, Bart RD, Gold E. Inapparent congenital cytomegalovirus infection-clinical and epidemiologic characteristics in early infancy. N Engl J Med. 1970 May;282(19): 1075-8.

41 Hanshaw JB. Congenital cytomegalovirus infection: a fifteen year perspective. J Infect Dis. 1971 May; 123(5):555-61.

42 Lanzieri TM, Dollard SC, Bialek SR, Grosse SD. Systematic review of the birth prevalence of congenital cytomegalovirus infection in developing countries. Int J Infect Dis. 2014 May;22: 44-8.

43 Lopo S, Vinagre E, Palminha P, Paixão MT, Nogueira $P$, Freitas MG. Seroprevalence to cytomegalovirus in the portuguese population, 2002-2003. Euro Surveill. 2011 Jun; 16(25):1-6. 
44 Ahumada-Ruiz S, Taylor-Castillo L, Visoná K, Luftig RB, Herrero-Uribe L. Determination of human cytomegalovirus genetic diversity in different patient populations in Costa Rica. Rev Inst Med Trop S Paulo. 2004 Mar-Apr;46(2):87-92.

45 Staras SAS, Dollard SC, Radford KW, Flanders WD, Pass RF, Cannon MJ. Seroprevalence of cytomegalovirus infection in the United States, 19881994. Clin Infect Dis. 2006 Nov;43(9):1143-51.

46 Neirukh T, Qaisi A, Saleh N, Rmaileh AA, Zahriyeh EA, Qurei L, et al. Seroprevalence of cytomegalovirus among pregnant women and hospitalized children in Palestine. BMC Infect Dis. 2013 Nov; 13:528.

47 Hamdan HZ, Abdelbagi IE, Nasser NM, Adam I. Seroprevalence of cytomegalovirus and rubella among pregnant women in western Sudan. Virol J. 2011 May;8:217.

48 Almeida LNB, Azevedo RS, Amaku M, Massad E. Cytomegalovirus seroepidemiology in an urban community of São Paulo, Brazil. Rev Saude Publica. 2001 Apr;35(2):124-9.
49 Souza MA, Passos AM, Treitinger A, Spada C. Seroprevalence of cytomegalovirus antibodies in blood donors in southern, Brazil. Rev Soc Bras Med Trop. 2010 Jul-Aug;43(4):359-61.

50 Serra FC, Machado J, Nicola MH, Jorge MCAS, Cruz LE, Giordano MV, et al. Soroprevalência de citomegalovírus em gestantes brasileiras de classe socioeconômica favorecida. DST J Bras Doenças Sex Transm. 2009;21(1):12-5.

51 Silva DFL, Carmo EL, Medeiros RF, Arruda LMF, Silva NF, Pinto WVM, et al. Estudo transversal de TORCS em gestantes e mulheres em idade fértil do Município de Juruti-Pa. In: Resumos do $49^{\circ}$ Congresso da Sociedade Brasileira de Medicina Tropical; 49. 2013 ago 6-10; Campo Grande, Brasil. Brasília: SBMT; 2013.

52 Silva DFL, Arruda LMF, Silva NF, Sagica FES, Moraes MM, JR JLSA, et al. Cytomegalovirus infections in patients with HIV/AIDS in a unit of health of the Amazonian Region, Belém, Pará, Brazil. J Med Microb Diagn. 2015 Apr;4(2):178. 